Www.jmscr.igmpublication.org

Impact Factor (SJIF): 6.379

Index Copernicus Value: 71.58

ISSN (e)-2347-176x ISSN (p) 2455-0450

crossref DOI: https://dx.doi.org/10.18535/jmscr/v6i4.81

Journal Of Medical Science And Clinical Research

IGM Publication

An Official Publication of IGM Publication

\title{
Indications and Patterns of Upper Gastro Intestinal Endoscopy Findings among Patients Attending A Tertiary Care Hospital, Kolkata, India
}

\author{
Authors \\ Dr Kalidas Biswas ${ }^{1 *}$, Dr Avick Nag ${ }^{2}$, Dr Indradip Maity ${ }^{2}$, Dr Jayanta Kumar Das ${ }^{3}$, \\ Dr Arup Chakraborty ${ }^{4}$ \\ ${ }^{1}$ Associate Professor, Dept of Medical Gastroenterology, Medical College, Kolkata, West Bengal, India \\ ${ }^{2}$ Post Graduate trainee, Department of General Medicine, Medical College Kolkata, West Bengal, India \\ ${ }^{3}$ Post Graduate trainee, Department of Anaesthesiology, Medical College Kolkata, West Bengal, India \\ ${ }^{4}$ Assistant Professor, Department of Community Medicine, Medical College, Kolkata, West Bengal, India \\ *Corresponding Author
}

Dr Kalidas Biswas

Residential address- BC 238, Samar Pally, Krishnapur, Kolkata 700102, West Bengal, India

Ph-03325719118, Mob-9433128722, Email: lipikakdb@gmail.com

\begin{abstract}
Introduction: Upper Gastrointestinal (UGI) endoscopy has become part and parcel of investigation protocol in a patient with gastrointestinal diseases. With passage of time it has been transformed to a therapeutic modality too. The present study was conducted to look for the indications and patterns of UGI endoscopy of certain GI and liver disorders in study hospital.

Materials and Methods: Patients undergoing UGI endoscopies referred from other departments and hospitals as well as from OPDs were assessed in our endoscopy clinic. Total 2466 patients who were examined at our endoscopy room were recorded over a period of the year 2016. The records were manually retrieved with the help of a predesigned semi-structured proforma and later on transformed to suitable statistical software and subsequently analysed.

Results: Out of 2466 patients 59\% were males and $41 \%$ were females. The commonest indication for doing UGI endoscopy was dyspepsia followed by evaluation for chronic liver disease (CLD) and UGI bleed. Other indications were corrosive injury and evaluation in patients with chance detection of Hepatitis $B$ and $C$ markers. Majority of dyspepsia patients were found to be normal on endoscopy. In dyspepsia patients a significant findings was esophago gastric malignancies. In CLD patients, commonest findings were esophageal varices in various stages. Patients presented with UGI bleed were noted to have esophageal varices in $18 \%$ of patients. Other causes of UGI bleed in this study were peptic ulcer disease, esophagogastric erosions and duodenal and gastric ulcers.About8\% patients of UGI bleed had underlying esophageal and gastric growth. A good majority of patients did not have any mucosal changes. Corrosive ingestion had produced spectrum of esophageal and gastric erosions as well as ulcers.

Discussion \& Conclusions: Patients attended for endoscopic evaluation were almost equal in sex distribution. Dyspepsia was the single most important indication for endoscopic examination and majority of them were found to be normal endoscopically. This implies that functional dyspepsia is probably the commonest etiology for dyspeptic patients. Among CLD patients portal hypertension (PHT) was evident in most of the patients with varices and portal hypertensive gastropathy (PHG). Patients presented with UGI bleed had varix in one fifth of cases and peptic ulcers in less than 10\% of patients. Thus UGI endoscopy is a very useful and informative procedure for diagnosis of GI and liver disorders.

Keywords: UGI endoscopy, indications, endoscopic patterns.
\end{abstract}




\section{Introduction}

UGI endoscopy has become very effective and popular as a diagnostic and therapeutic modality. To reach diagnosis in common gastrointestinal (GI) diseases it is almost indispensible. It helps the clinician to visualise exact changes of many disease processes and to meet a diagnosis serendipitously. It enables us to intervene at various stages of the disease as a therapeutic modality. Use and acceptance of this procedure is increasing day by day to both doctors and patients. In our tertiary care teaching hospital setup we had done UGI endoscopy and encountered many a diagnoses in a span of a year. We tried to evaluate the pattern of our finding and compare the findings to other national and international studies. In our medical college we need to see referrals from other departments of the college and patients attending particularly from all over west Bengal and adjoining states. We wanted to share our experience especially in view of the fact that this sort of data is very scanty not only from our state but also from a national scenario.

\section{Materials and Methods}

This study was undertaken at Endoscopy clinic of our department over a period year 2016, the patients comprised of persons attending our various OPDs and admitted to inpatient departments of our hospital. The patient population was varied in regards to age, sex and presenting complaints. Patients were examined in both emergency situation and non-emergency situation with prior appointment. Informed consent was taken in all patients. Topical anesthesia with lignocaine spray (10\%) and lignocaine jelly ( $2 \%$ ) were used, no patients were given sedation. Endoscopy was done with PENTAX -EPKP model. All findings were recorded manually and were retrieved subsequently. The indications and findings and in some cases suggestions were recorded. Biopsy for histopathological examination was taken for suspected cases. Variceal ligation and sclerosant injection were used when situation demands. We were fortunate to have no untoward adverse events in the entire duration of study. No mortality was also noted during the procedure.

\section{Statistical Analysis}

The primary data of patient's symptoms and the endoscopy findings were collected in a predesigned semi-structured proforma. The secondary data was collected from out-patient (OP) and bed head ticket (BHT) of the patients. The data was entered in Microsoft Excel (version 2007) software and analyzed after that. The information was represented with mean, standard deviation for continuous variables and frequency, percentages for categorical variables. Finally the result was represented with suitable Bar and Pie charts.

\section{Results}

Total 2486 endoscopies were done in the year 2016 at our department. Male to female ratio was $3: 2$.The age incidence in case of female was 1296 years and in male patients it was 16-86 years. The commonest in all groups was dyspepsia; the other common indications were evaluation for chronic liver disease (CLD), UGI bleed, corrosive injury, chance detection of $\mathrm{HBsAg}$ and anti-HCV positivites. .(Figure.1-A,B,C) Pertinent findings were $68 \%$ patiens with dyspepsia were endoscopically normal and important observation was patients with this problem often found to have malignancy of UGI $\operatorname{tract}(3 \%)$. Duodenal and gastric ulcer were not very common; we recorded very few GERD cases in our study. Erosions including several types of gastritis were noted in a considerably larger group. (Figure. 2)

Among patients with chronic liver diseases varices was found in $58.5 \%$ cases, $13 \%$ of the patients had Mild portal hypertensive gastropathy. Other findings included oesophageal stricture in $1 \%$, oesophageal candidiasis in $1 \%$, hiatus hernia in $2 \%$, duodenal bleed in $4 \%$, Gastric antral vascular ectasia in $2 \%$, Gastric erosion in $1 \%$ and no findings in $15 \%$ cases (Figure. 3).

Patients attended with history of UGI bleed were seen to have varices in $17 \%$ of population , duodenal and gastric ulcer constituted $10 \%$ of 
cases, erosions involving gastric duodenal and esophageal were one of the commonest findings . Upper digestive tract malignancies were seen to have presented in around $7 \%$ cases with UGI bleed. Mallory Weiss tear was noted in a small minority. Significantly a large population of patients had no detectable abnormality as a cause of UGI bleed possibility due to late hospital attendance, minor and reversible changes .(Figure. 4)

Patients with history of corrosive ingestion had gastric ulcer and erosion in around 60\% patients. Esophageal injury including ulcer and erosion were noted in $20 \%$ subjects. However $18 \%$ of

Figure 1-A Sex ratio of study population $(n=2486)$

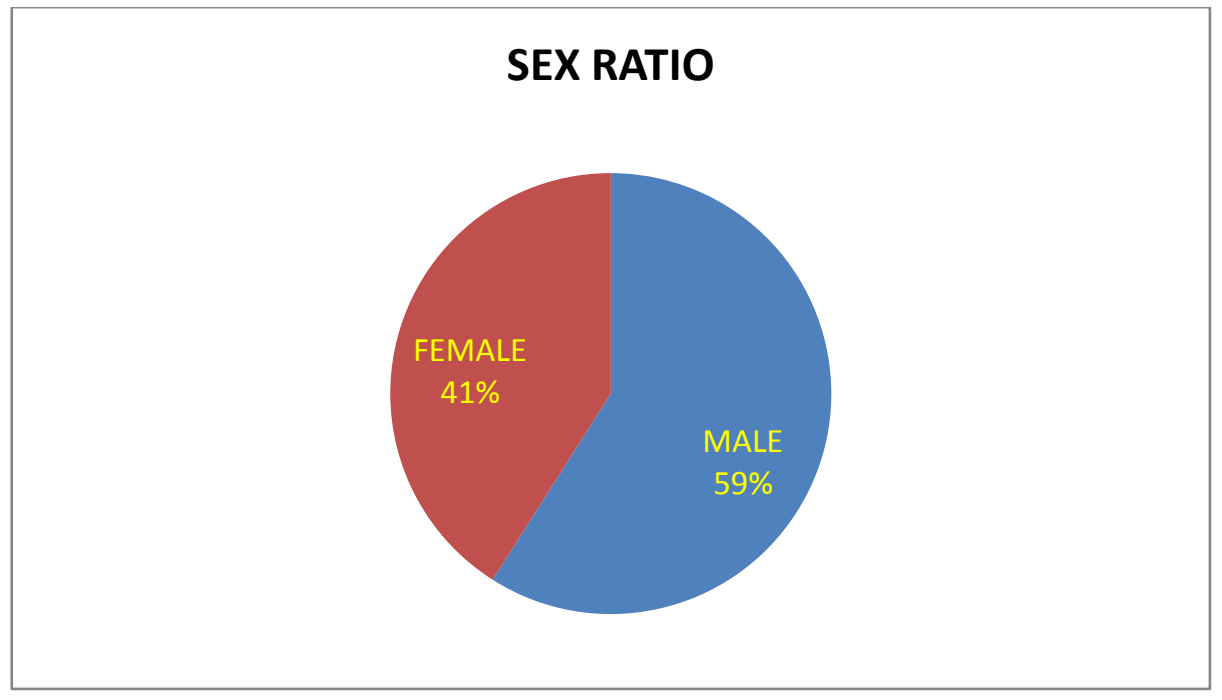

Figure 1-B Age distribution of male study subjects $(\mathrm{n}=2486)$

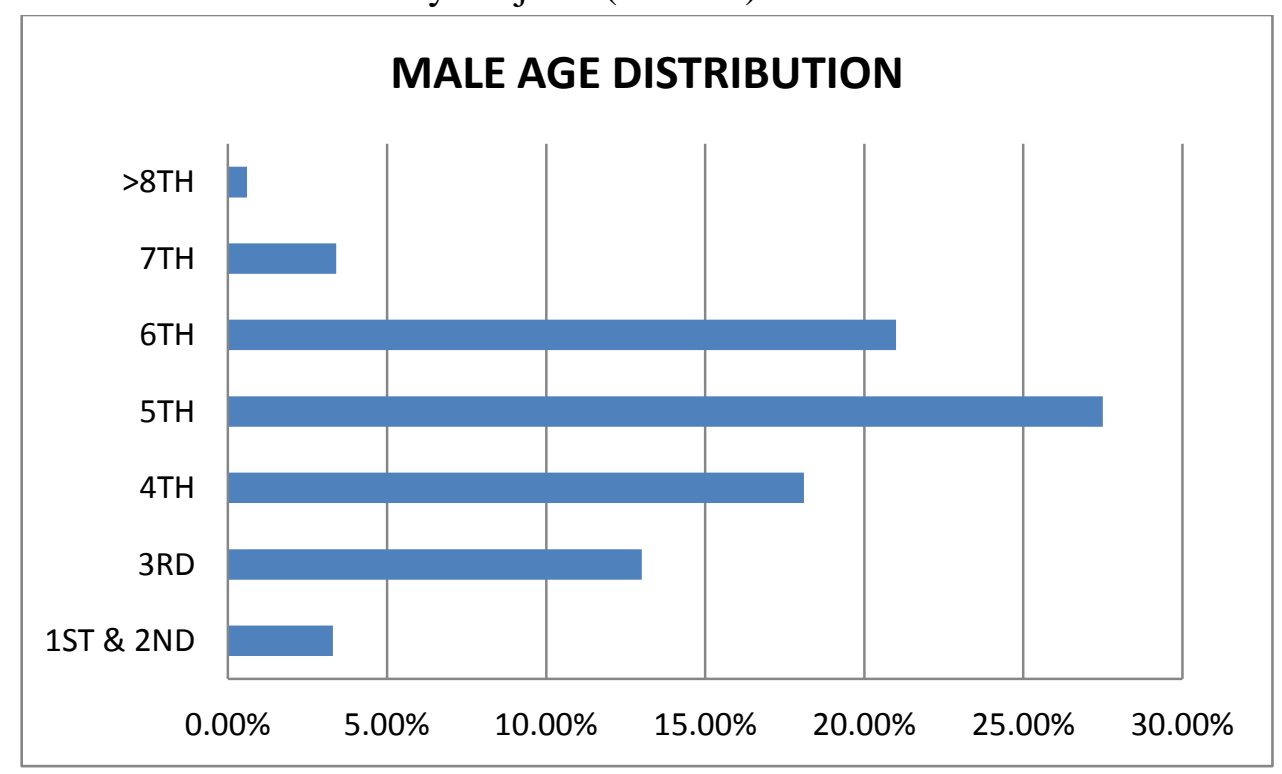


Figure 1-C Age distribution of female study subjects

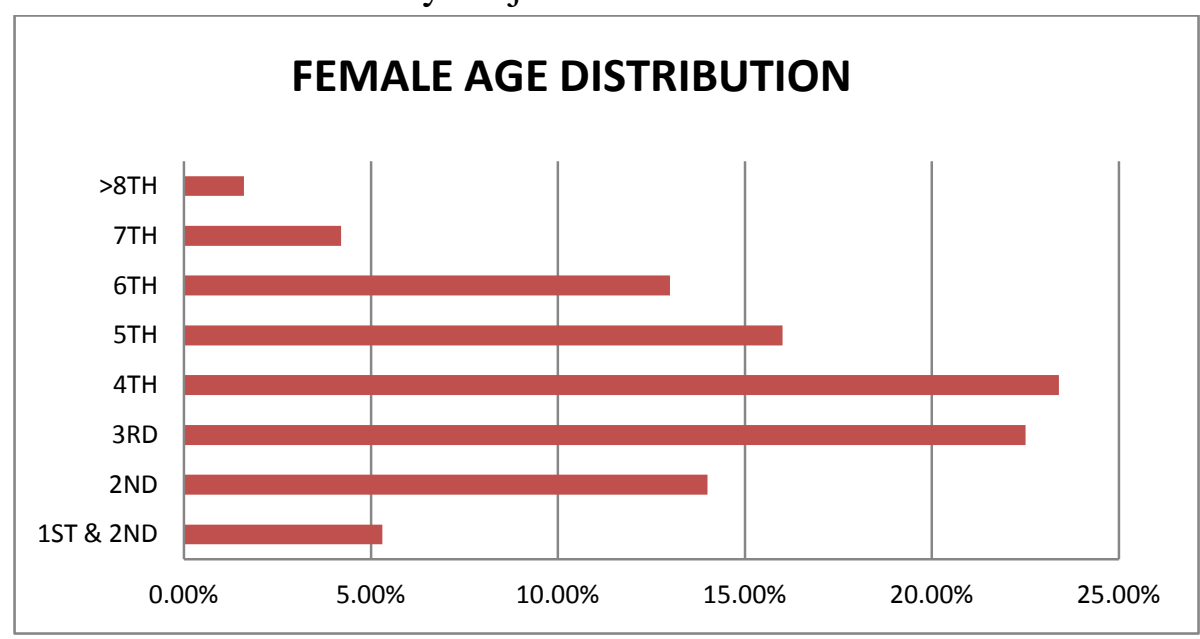

Figure 2 Patterns of UGI findings among dyspepsia patients

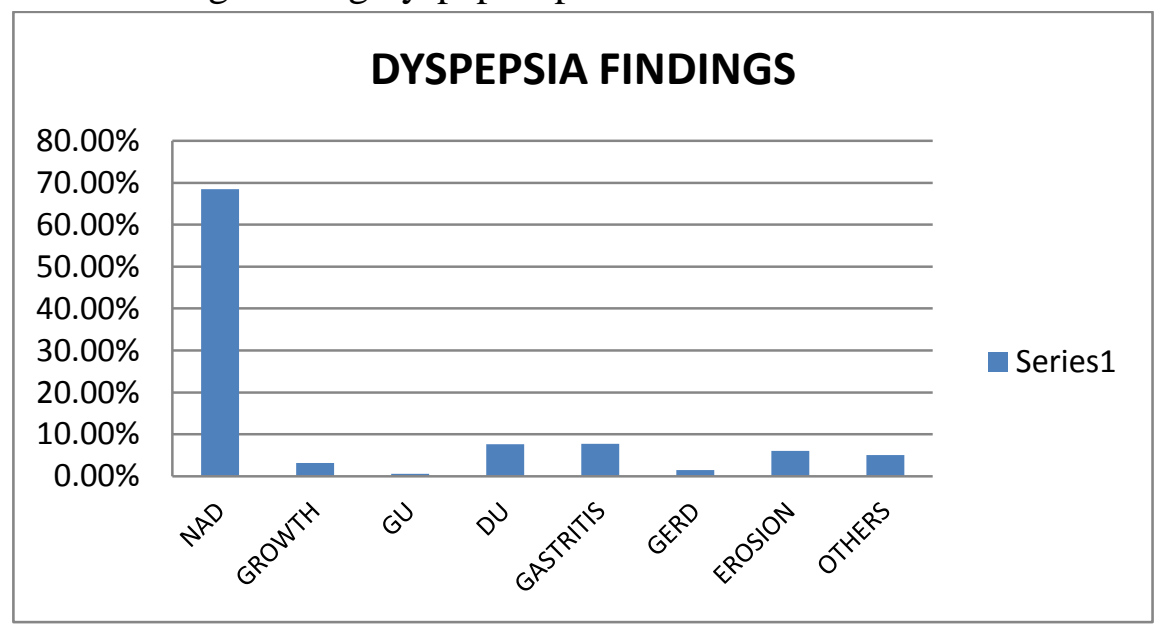

Figure 3 Patterns of UGI findings among Chronic Liver Disease (CLD) patients

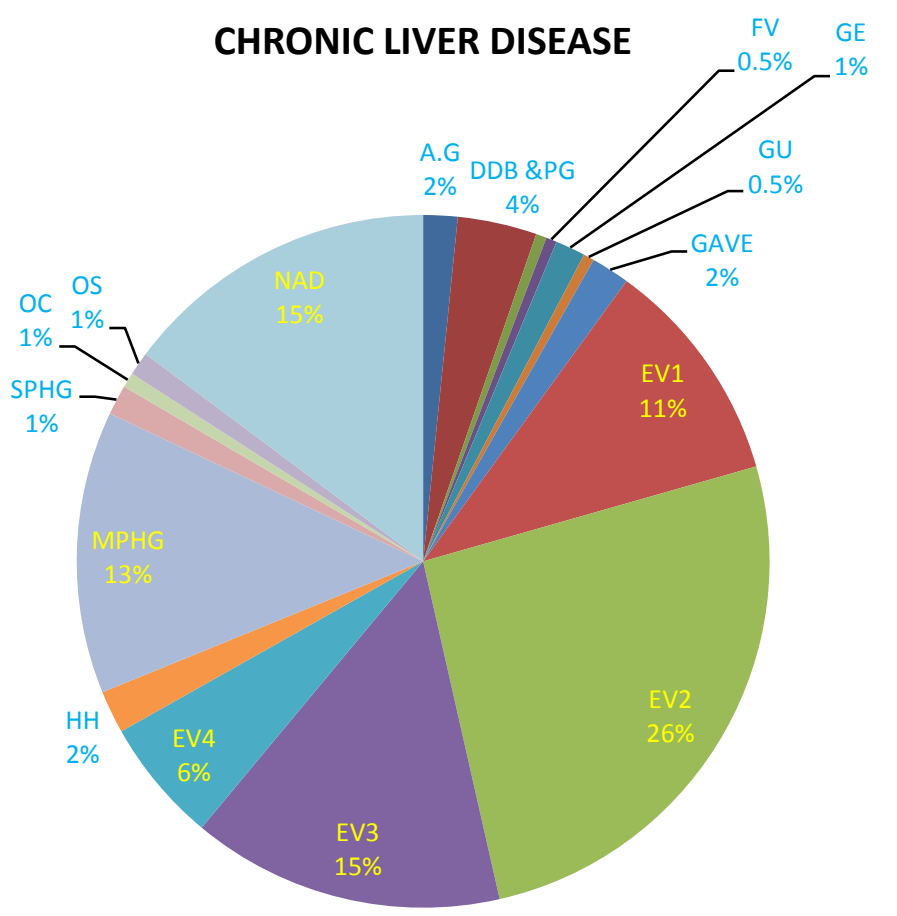

A.G.- Antral Gastritis

DDB \& PG- Deformed duodenal

bulb \& Pangastritis

FV- Fundal varix

GE -Gastric erosion

GU-Gastric Ucer

GAVE- Gastric antral vascular

ectasia

EV1 TO EV4-Grade 1 to 4

esophageal varix

$\mathrm{HH}$-Hiatus hernia

MPHG-Mild PHG

SPHG- Severe PHG

OC- EesophagEal candidiasis

OS-Esophageal Stricture

NAD- Normal 
Figure 4 Patterns of UGI findings among patients presented with upper GI bleed

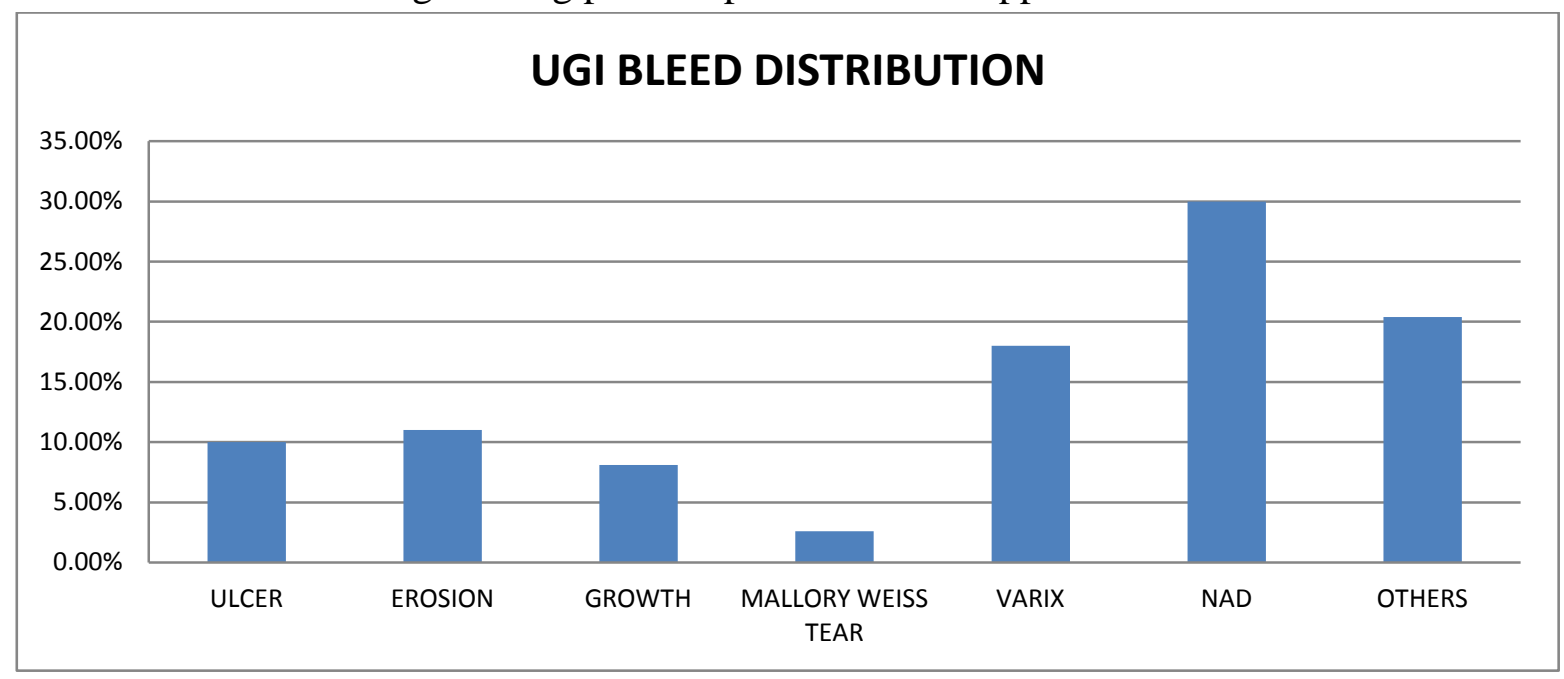

Figure 5 Patterns of UGI endoscopy among patients admitted with corrosive ingestion

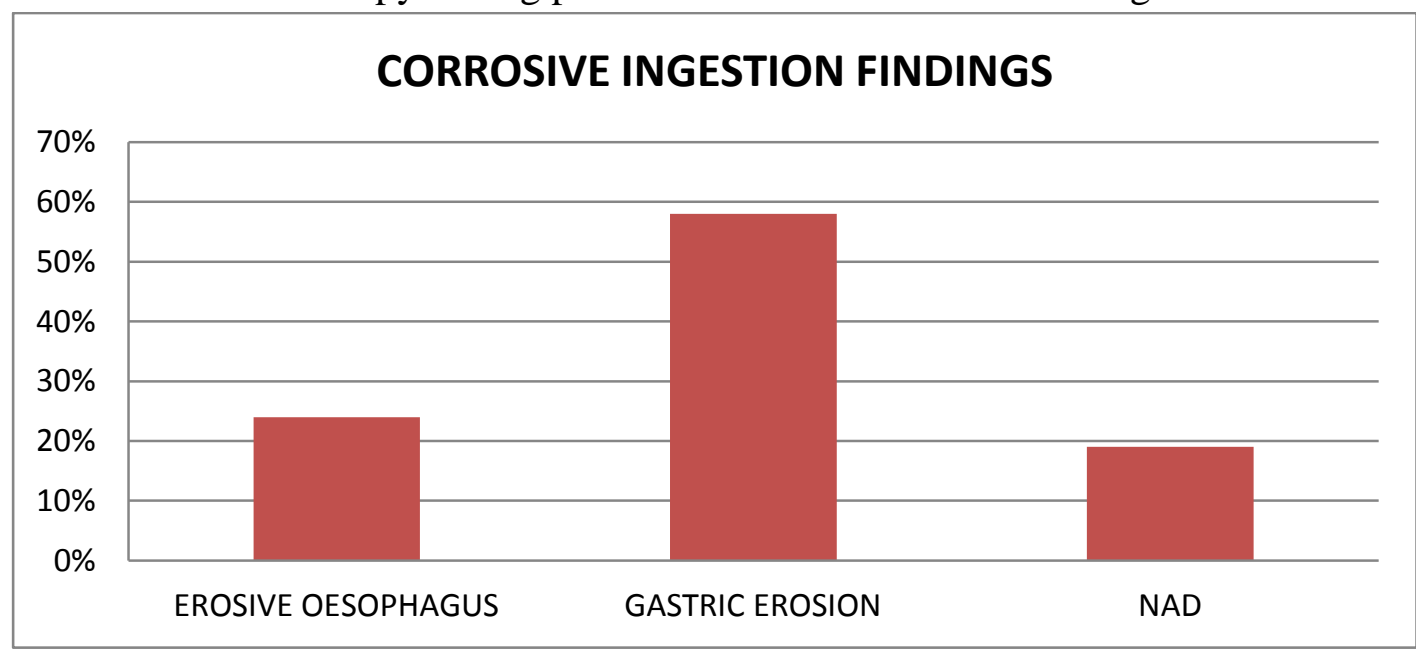

Figure 6 Patterns of UGI findings among seropositive patients with Hepatitis B

\section{HEPATITIS B ENDOSCOPIC FINDINGS}

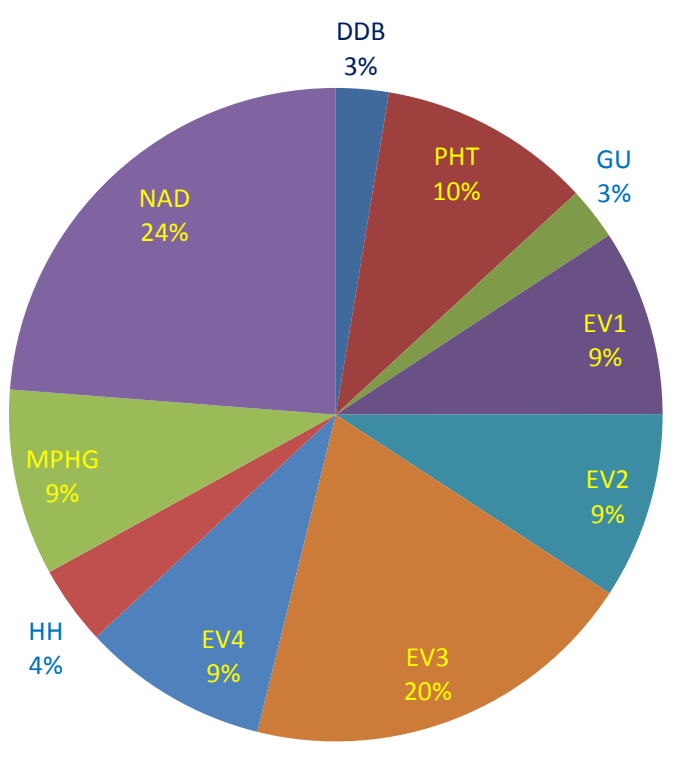

DDB-Deformed

duodenal bulb

PHT- Portal hypertension

GU- Gastric ulcer

MPHG-Mild PHG

gastropathy

$\mathrm{HH}$ - Hiatus hernia

EV1 TO EV4-

Grade 1 to 4

esophageal varix

NAD-Normal 
Figure 7 Patterns of UGI findings among seropositive patients with Hepatitis C

\section{HEPATITIS C ENDOSCOPIC FINDINGS}

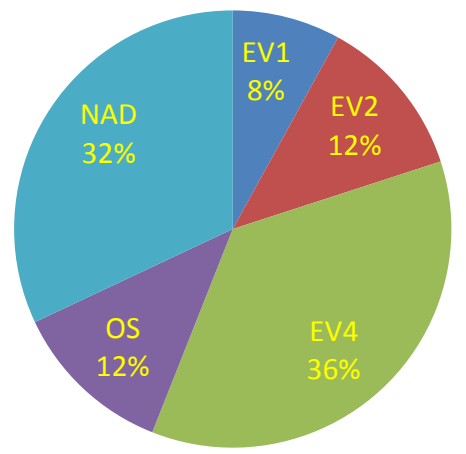

EV1 to EV4- Esophageal varix grade 1 to 4 OS- Esophagitis NAD- Normal

\section{Discussion}

In our study conducted over a period of one year 2016 we catered to a population who were referred to our endoscopy unit for evaluation of causes of UGI co-morbidities. There were no procedural complications during the study period and the procedure was performed under local anaesthesia, other studies also did not find any morbidity in patients who underwent UGIscopy without anesthesia ${ }^{1 .}$

The male population was $59 \%$ and the female population was $41 \%$, among males majority $28 \%$ was in $5^{\text {th }}$ decade and females majority $23 \%$ was in the $4^{\text {th }}$ decade .In this study there were more males than females similar to findings in majority of other countries, probably because UGI tract diseases are more prevalent in males ${ }^{2-6}$

The commonest indication of performing an UGI study was dyspepsia in which the cause could not be ascertained in $68 \%$ cases, the other causes of dyspepsia were Gastritis $8 \%$, duodenal ulcer $7 \%$, GERD $1 \%$, Erosion $6 \%$ and growth in $2 \%$ of the cases. A study in USA found that UGI was normal in $58 \%$ cases of dyspepsia. ${ }^{7}$. Another study in Chattisgarh found the study to be normal in $40 \%$ patients with dyspepsia. ${ }^{8}$ A large Indian study involving employees of a govt sector also corroborated that dyspepsia was a predominant symptom to go for UGI scopy. ${ }^{9}$

Among cases of Upper GI bleed, varices occurred in $18 \%$ cases, ulcer in $10 \%$, erosion in $12 \%$, growth in $8 \%$ and miscellaneous causes in $20 \%$, no cause could be found in $30 \%$ cases. These findings were bit different from another study in which they found varix in more than $50 \%$ cases. ${ }^{10}$ In patients with corrosive ingestion findings such as gastric erosion was found in $58 \%$ cases, oesophageal erosion was found in $22 \%$ cases and the study was normal in $19 \%$ of the cases.

Patients who were evaluated for CLD was detected to have varices in many grades in around $3 / 5^{\text {th }}$ cases, portal hypertensive gastropathy (PHG) and gastric antral vascular ectasia (GAVE) were seen in $15 \%$ of the patients. Duodenal ulcer and deformed duodenal bulb was seen in a small minority. However $15 \%$ of CLD patients had no endoscopic abnormalities. In a journal published from tropical countries the findings were different which showed esophageal varices were diagnosed in $96.4 \%$ patients. In that study esophageal mucosal findings observed were erosions $(7.1 \%)$, ulcer $(1.8 \%)$, candidiasis $(8.9 \%)$ while one $(1.8 \%)$ patient had both esophageal erosions and candidiasis. Gastric varices were observed in 11 $(19.6 \%)$ patients and the analysis showed that the most frequent form was isolated gastric varices type 1 (IGV1) was recorded in six (10.7\%) patients. Portal hypertensive gastropathy (PHG) was seen in $45(80.4 \%)$ patients. Other gastric mucosal lesions were erosions (12.5\%) and ulcers $(10.7 \%)$. Duodenal varices were not seen in any of the patients ${ }^{11}$ 
Patients who were evaluated for HbsAg positivity had various grades of varices in half of patients, changes suggestive of PHG was around 19\% patients. One fourth of all patients did not have any mucosal changes.

Of all Anti-HCV positive patients more than 50\% patient population had various grades of oesophageal varix. One third patients had no detectable mucosal abnormalities.

\section{Conclusion}

Spectrum of changes noted in our study population revealed that UGI endoscopy is an important tool for understanding the extent and severity as well as variability of GI and liver diseases. Functional dyspepsia is the commonest diagnosis for patients undergoing UGI endoscopy. Esophageal varix is the commonest cause for UGI bleed in our patients. Chance detection of GI malignancy in patients with dyspepsia is a very important observation in our series.

Sources of support in the form of grants-NIL

\section{References}

1. Safety of non-anesthesia provider administered propofol sedation in nonadvanced gastrointestinal endoscopic procedures: A meta-analysis. Basavana Gouda, Gowri Gouda, Anuradha Borle, Akash Singh, Ashish Sinha, and Preet M. Singh . Saudi J Gastroenterol. 2017 MayJun; 23(3): 133-143.

2. Olokoba $\mathrm{AB}$, Bojuwoye BJ. Indications for oesophagogastroduodenoscopy in Ilorin, Nigeria--a 30 month review. Nigerian Journal of clinical Practice. 2010; 13(3): 260-3.

3. Agbakwuru EA, Fatusi AO, Ndububa DA et al. Pattern and validity of clinical diagnosis of upper gastrointestinal diseases in southwest Nigeria. Afr Health Sci. 2006; 6(2): 98-103.

4. Malu AO, Wali SS, Kazmi R, Macauley D, Fakunle YM. Upper gastrointestinal endoscopy in Zaria, northern Nigeria. West
African Journal of Medicine. 1990; 9(4): 279-84.

5. Danbauchi SS, Keshinro IB, Abdu-Gusau K. Fifteen years of upper gastrointestinal endoscopy in Zaria (1978 - 1993). African journal of medicine and medical sciences. 1999; 28(1-2): 87-90.

6. Aduful H, Naaeder S, Darko R, Baako B, Clegg-Lamptey J, Nkrumah K, et al. Upper gastrointestinal endoscopy at the korlebu teaching hospital, accra, ghana. Ghana Med J. 2007; 41(1): 12-6

7. Low Prevalence of Clinically Significant Endoscopic Findings in Outpatients with Dyspepsia Khaled Abdeljawad, Antonios Wehbeh, and Emad Qayed. Gastroenterology Research and Volume 2017 (2017), Article ID 3543681, 7 pages

8. Upper Gastro Instestinal Endoscopic Findings In Patients With Dyspepsia: Our Experience At Cims, Bilaspur, Chhattisgarh, India. YasmeenKhan , S.K. Mohanty, Hemant Kumar, Sachin Pandey. IOSR Journal of Dental and Medical Sciences (IOSR-JDMS) e-ISSN: 2279-0853, p-ISSN: 2279-0861. Volume 13, Issue 5 Ver. VI. (May. 2014), PP 08-12

9. Trends in Endodiagnosis of Upper Gastrointestinal Diseases at a Referral Railway Hospital. Gautam Ray, Subroto Pal. Journal of Digestive Endoscopy 2011;2(4):213-19

10. Etiological and Endoscopic Profile of Middle Aged and Elderly Patientswith Upper Gastrointestinal Bleeding in a Tertiary Care Hospital in North India: A Retrospective Analysis, PranavMahajan and Vijant Singh Chandail. J Midlife Health. 2017 Jul-Sep; 8(3): 137-141.

11. Upper Gastrointestinal endoscopy in patients with liver cirrhosis. Spectrum and prevalence of lesions. A Akere, O Akande. Annals of tropical medicine and public health.2016;9(2):112-118. 